\title{
Primary malignant mucosal melanoma of the maxillofacial area
}

\author{
Hyounmin Kim¹, Sanghoon Lee ${ }^{2}$, In-Ho Cha ${ }^{1}$, Hyung Jun Kim¹, Woong Nam ${ }^{1}$ \\ ${ }^{1}$ Department of Oral and Maxillofacial Surgery, Yonsei University College of Dentistry, Seoul, \\ ${ }^{2}$ Oral Oncology Clinic, Research Institute and Hospital, National Cancer Center, Goyang, Korea
}

\begin{abstract}
J Korean Assoc Oral Maxillofac Surg 2021;47:76-81)
Objectives: We aimed to collect and report data from all patients who have been diagnosed with mucosal malignant melanoma to obtain the epidemiology and principles of current treatments.

Materials and Methods: Between January 2008 and December 2018, 20 patients underwent surgery or follow-up observations at Yonsei University Dental Hospital. The patients' clinical information was reviewed retrospectively.

Results: Seventeen of 20 patients had undergone definitive surgery, while only 6 patients received adjuvant radiotherapy or systemic therapy. Eight of 20 patients, including those that had recurrent lesions, were provided immunotherapy. The 3-year survival for all stages was $50 \%$, with a local recurrence rate of $75 \%$ and a metastasis rate of $65 \%$.

Conclusion: The overall survival of patients receiving surgical treatment was longer than that of patients who did not undergo surgical resection. Eight of 20 patients received immunotherapy as the first-line regimen at our clinic, and those patients exhibited longer overall survival compared to patients in reported keynote studies.
\end{abstract}

Key words: Malignant melanoma, Immunotherapy, Oral cancer

[paper submitted 2020. 10. 14 / revised 2020. 12. 21 / accepted 2020. 12. 28]

\section{Introduction}

Malignant melanoma occurs mainly in cutaneous form but is very rarely seen in mucosal form. Mucosal melanoma of the head and neck composes $0.7 \%$ to $0.8 \%$ of total malignant melanomas and $8 \%$ of total malignant melanomas of the head and neck ${ }^{1,2}$. The median age of such patients is 70 years, and the incidence rate is twice that of Caucasians' than that of Americans' ${ }^{3}$. The lesion is very invasive, with a 5-year survival rate of $25 \%$ to $34 \%$ with a poorer prognosis than mucosal or vulvar form ${ }^{4-7}$.

Treatment type and prognosis are unclear due to the rarity of the tumor and its short survival period ${ }^{8}$. However, for

\footnotetext{
Woong Nam

Department of Oral and Maxillofacial Surgery, Yonsei University College of Dentistry, 50-1 Yonsei-ro, Seodaemun-gu, Seoul 03722, Korea

TEL: +82-2-2228-8744

E-mail:omsnam@yuhs.ac

ORCID: https://orcid.org/0000-0003-0146-3624

(c) This is an open-access article distributed under the terms of the Creative Commons Attribution Non-Commercial License (http://creativecommons.org/ licenses/by-nc/4.0/), which permits unrestricted non-commercial use, distribution, and reproduction in any medium, provided the original work is properly cited. Copyright (C) 2021 The Korean Association of Oral and Maxillofacial Surgeons. All rights reserved.
}

resectable tumors, the most common treatment is complete surgical resection ${ }^{9-11}$. Adjuvant radiotherapy is recommended to prevent local recurrence ${ }^{9,12}$, but the exact regimen of survival benefits of definitive/adjuvant systemic therapy are not currently reported ${ }^{13}$.

Since malignant mucosal melanoma of the head and neck was first reported by Lincoln in 1885, approximately 1,000 cases have been published ${ }^{14}$. This report compares the treatment received by 20 patients diagnosed with malignant mucosal melanoma in the head and neck and evaluates the effectiveness of immunotherapy.

\section{Materials and Methods}

This study was approved by the Institutional Review Board of Yonsei University Dental Hospital (IRB No. 2-2019-0075) and the written informed consent was waived by the IRB.

Among the 25 patients diagnosed with malignant mucosal melanoma who visited Yonsei University Dental Hospital from January 2008 to December 2018, the medical records of 20 were reviewed; the other 5 patients had undergone surgery and observation at other clinics or departments.

The patients' clinical information of treatment, adjuvant 
chemotherapy, survival or most recent observation time, presence or absence of recurrence or metastasis, and age at death was obtained retrospectively based on written and electronic medical records.

In the 20 patients who were suspected of cancer and visited the clinic, incisional biopsy was performed. Computed tomography and positron emission tomography imaging was conducted on patients confirmed with mucosal malignant melanoma to examine the scope of surgery and metastasis. All biopsies were reviewed and diagnosed by one or more oral pathologists.

Survival analysis was completed with using the KaplanMeier method, while survival curve comparisons were performed using the log-rank test. The categorical variables were compared using the chi-square test, with statistical significance assigned at $P<0.05$. Statistical processing of the data was performed with IBM SPSS Statistics (ver. 25.0; IBM, Armonk, NY, USA).

Table 1. Patient demographics $(n=20)$

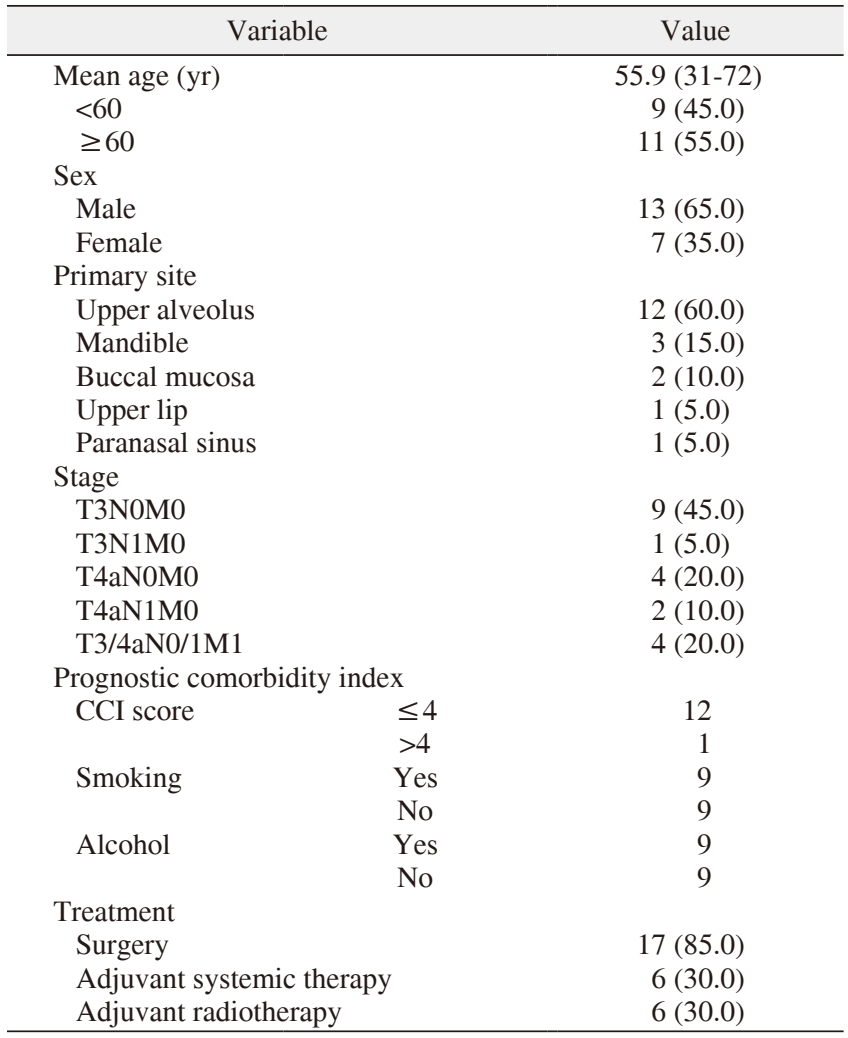

(CCI: Charlson comorbidity index)

Values are presented as mean (range), number (\%), or number only. Hyounmin Kim et al: Primary malignant mucosal melanoma of the maxillofacial area. $J$ Korean Assoc Oral Maxillofac Surg 2021

\section{Results}

\section{Patient demographics}

The mean age of the patients at first diagnosis was 55.9 years (range, 31-72 years). The most common area was the maxillary alveolus $(n=12,60.0 \%)$, and the TNM stage was T3N0M0 ( $=9,45.0 \%)$. Patient demographics are summarized in Table 1.

\section{Treatment}

Seventeen patients diagnosed with resectable locoregionally advanced melanoma underwent surgery, while the other 3 patients diagnosed with metastatic malignant mucosal melanoma were not operated on but instead underwent palliative chemotherapy. Of the 17 patients who underwent surgery, only 6 were provided adjuvant radiotherapy. The rest of the patients obtained free or dysplasia-level surgical margin or died before the start of radiotherapy. In the case of chemotherapy, 6 of the 17 patients undergoing surgery also received chemotherapy. In the remaining patients, systemic therapy was not performed for the same reasons as for radiotherapy. A total of 8 patients was administered immunotherapy, but 2 ceased immunotherapy due to metastasis to other organs. Three patients exhibited disease-free survival of 4 to 22 months, but treatment was suspended due to critical systemic side effects. Another 2 of these patients showed 4 to 16 months of disease-free survival with side effects. Treatment by patient and stage is summarized in Fig. 1.

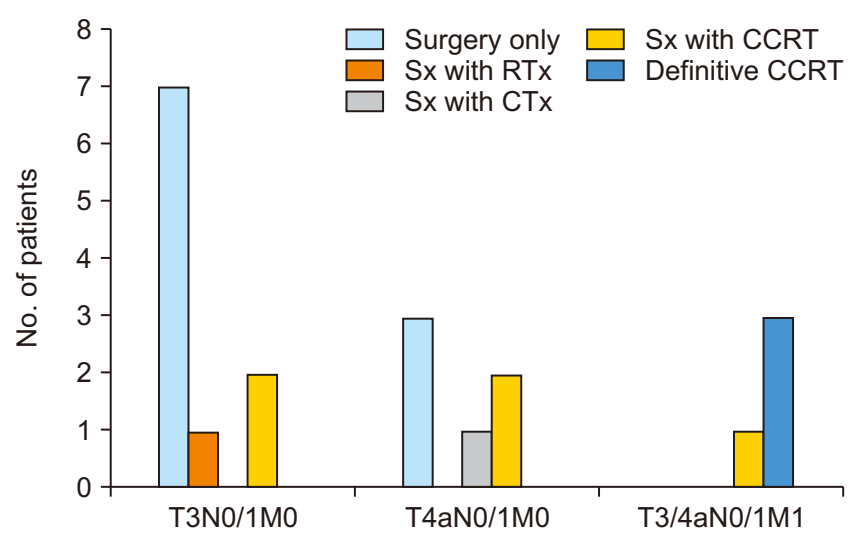

Fig. 1. Treatment by clinical stage in this study. (Sx: surgery, RTx: radiotherapy, CTx: systemic therapy, CCRT: concurrent chemoradio therapy)

Hyounmin Kim et al: Primary malignant mucosal melanoma of the maxillofacial area. $J$ Korean Assoc Oral Maxillofac Surg 2021 


\section{Survival rates}

The mean overall survival was 44.3 months (range, 1-152 months). For all stages, the 3-year survival rate was 50\%, the 5 -year survival was $32 \%$, the recurrence rate was $75 \%$, and the metastasis rate was $65 \%$. For T3N0M0, overall survival was 68.5 months (range, 1-152 months), the 3-year recurrence rate was $45 \%$, and the metastasis rate was $40 \%$. For T3N1M0 at 12 months, these values were $0 \%, 0 \%$, and $0 \%$, respectively. These variables for T4N0M0 were 37.8 months (range, 31-50 months), 100\%, and 75\%, respectively, and for T4aN1M0 were 46 months (range, 31-93 months), 100\%, and $100 \%$. Overall survival and survival rate by stage are summarized in Fig. 2 and 3.

\section{Immunotherapy}

Eight patients were provided immunotherapy as either the first line or the second line of defense in parallel with surgical

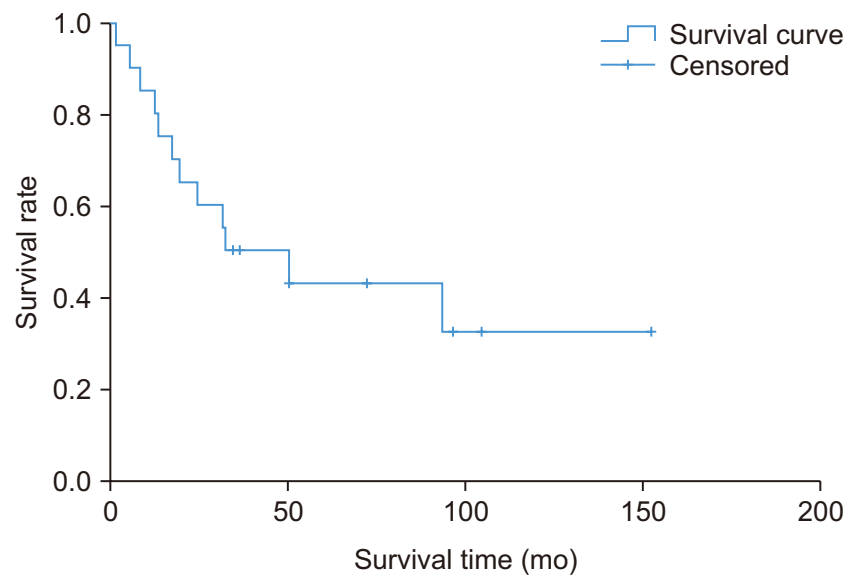

Fig. 2. Overall survival rate with survival time in this study. Hyounmin Kim et al: Primary malignant mucosal melanoma of the maxillofacial area. $J$ Korean Assoc Oral Maxillofac Surg 2021

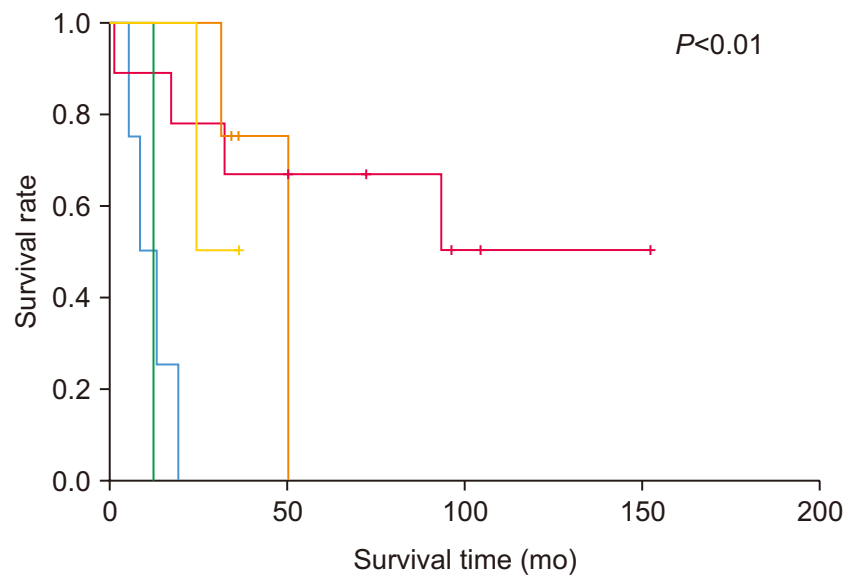

treatment. The 3-year survival rate was $41.7 \%$, and the 5-year survival rate was $27.8 \%$ for all 12 patients with no immunotherapy. Within 3 years, the recurrence rate was $16.7 \%$ with a metastasis rate of $25 \%$. The 3 -year recurrence rate and metastasis rate were $25 \%$ in all 4 patients with immunotherapy as the primary treatment. In addition, the 3-year metastasis rate in all 4 patients with secondary treatment of immunotherapy after surgical treatment alone or conventional therapy (adjuvant systematic therapy or concurrent chemo-radio therapy) was $25 \%$. Information on patients with immunotherapy and their survival rates are summarized in Tables 2 and 3 and Fig. 4.

\section{Discussion}

Malignant mucosal melanoma is a rare disease, with a prevalence less than $1 \%$ of all melanomas including cutaneous forms and of less than $10 \%$ of all melanomas of the head and neck. Although staging of mucosal melanoma is challenging due to the lack of clear parameters affecting the survival rate, existing TNM staging based on the size of the tumor, was reported to be significant in predictions of over-

Table 2. Partition of immunotherapy among patients and their responses at 3 years

\begin{tabular}{lccc}
\hline & $\begin{array}{c}\text { Survival rate } \\
(\%)\end{array}$ & $\begin{array}{c}\text { Recurrence } \\
(\%)\end{array}$ & $\begin{array}{c}\text { Metastasis } \\
(\%)\end{array}$ \\
\hline $\begin{array}{l}\text { Conventional therapy } \\
(\mathrm{n}=12,60.0 \%)\end{array}$ & 41.7 & 16.7 & 25.0 \\
$\begin{array}{l}\text { Immunotherapy as the } \\
\text { first line } \\
(\mathrm{n}=4,20.0 \%)\end{array}$ & 21.7 & 25.0 & 25.0 \\
$\begin{array}{l}\text { Immunotherapy as the } \\
\text { second line } \\
(\mathrm{n}=4,20.0 \%)\end{array}$ & 100 & - & 25.0 \\
\hline $\begin{array}{l}\text { Hyounmin Kim et al: Primary malignant mucosal melanoma of the maxillofacial area. } J \\
\text { Koun }\end{array}$
\end{tabular}

Korean Assoc Oral Maxillofac Surg 2021
Fig. 3. Overall survival rate by clinical stages with survival time in this study $(P<0.01)$.

Hyounmin Kim et al: Primary malignant mucosal melanoma of the maxillofacial area. J Korean Assoc Oral Maxillofac Surg 2021 
Table 3. Characteristics of patients with immunotherapy

\begin{tabular}{|c|c|c|c|c|c|c|}
\hline Patient No. & Stage & $\begin{array}{l}\text { Primary location } \\
\text { of the tumor }\end{array}$ & Surgery & $\begin{array}{l}\text { Adj. RTx } \\
\text { (Gy) }\end{array}$ & Immunotherapy & Survival (mo) \\
\hline 1 & T4aN0M0 & Upper alveolus & WE & 50 & Pembrolizumab & Censored (93) \\
\hline 2 & T3N1M0 & Floor of mouth & $\mathrm{WE}+\mathrm{ND}$ & 82.7 & Pembrolizumab & Alive (12) \\
\hline 3 & T4aN1M1 & Upper alveolus & - & - & Ipilimumab & Death (5) \\
\hline \multirow[t]{2}{*}{4} & T3N0M0 & Mandible & WE & - & - & - \\
\hline & rT4bNxM0 & Mandible & WE & - & Pembrolizumab & Alive (72) \\
\hline \multirow[t]{2}{*}{5} & T3N0M0 & Upper alveolus & $\mathrm{WE}+\mathrm{ND}$ & 50 & - & - \\
\hline & rT3NxM0 & Soft palate & WE & 39.6 & Pembrolizumab & Alive (50) \\
\hline \multirow[t]{2}{*}{6} & T3NOM0 & Upper lip (mucosal) & WE & 60 & - & - \\
\hline & rT4aN0M0 & Mandible & WE & - & Pembrolizumab & Alive (152) \\
\hline 7 & T4aN1M0 & Upper alveolus & $\mathrm{WE}+\mathrm{ND}$ & 63.6 & Pembrolizumab & Death (24) \\
\hline 8 & T4aN1M0 & Upper alveolus & $\mathrm{WE}+\mathrm{ND}$ & 50 & Pembrolizumab & Alive (36) \\
\hline
\end{tabular}

(WE: wide excision, ND: neck dissection, Adj.: adjuvant, RTx: radiotherapy)

Hyounmin Kim et al: Primary malignant mucosal melanoma of the maxillofacial area. J Korean Assoc Oral Maxillofac Surg 2021

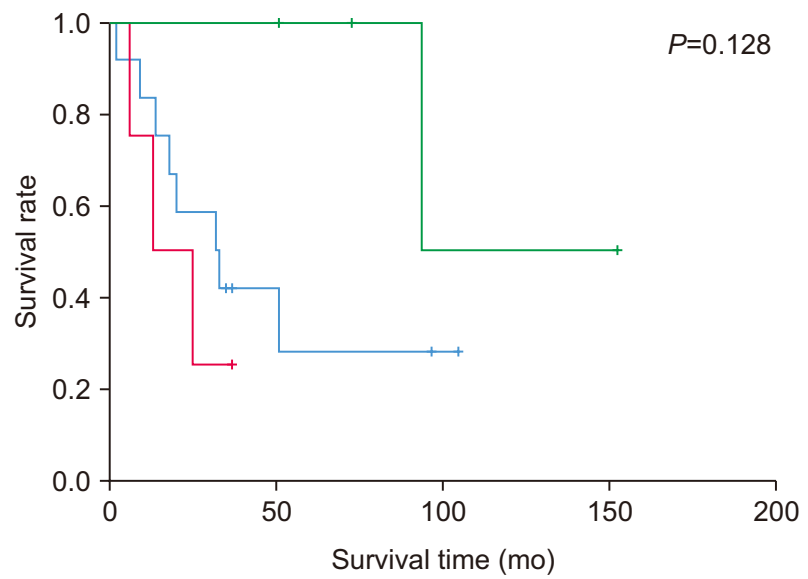

Treatment

$\neg$ Conventional therapy only

$\neg$ Immuno therapy as 1st line

$\square$ Immuno therapy as 2nd line

1 Censored

- Censored

1 Censored all survival and progress-free survival compared to staging based on degree of local recurrence, distant metastasis, or depth of invasion in cases of sinonasal melanoma. The older was the person, the higher was the prevalence rate, with most patients in their 70s, a similar age at diagnosis to that of cutaneous melanoma ${ }^{15}$. Most of the epidemiological and clinical data in this study were comparable to those reported in the literature. Twenty patients with malignant mucosal melanoma of the head and neck were analyzed. The average age of the patients was 55.9 years, and the oldest was 72 years, with an average observation period of 44.3 months (range, 1-152 months), which is not significantly different from that of other published studies. The prevalence of men was higher in our clinic compared to studies that reported women to have more common outbreaks than men ${ }^{16,17}$ and reports that there was no difference in prevalence between men and women ${ }^{15}$.

Although no principles of proper management or prognosis have been established due to the rarity of the tumor and its short survival rate ${ }^{8}$, radiotherapy is strongly recommended for patients with resectable tumors within 6 weeks after complete resection ${ }^{9}$. However, there are no reports on a clear survival benefit of systemic therapy ${ }^{1,9-13}$. In our clinic, surgical resection was prioritized in patients $(\mathrm{n}=17,85.0 \%)$ with resectable primary lesions without distant metastasis. Patients with positive surgical margin or with local recurrence underwent radiotherapy. Systemic therapy was performed regardless of the surgical margin if node metastases or adjacent invasion was present. The mean survival is 49.8 months when accompanied by surgical treatment, but it decreased to 12.3 months when radiotherapy or systemic therapy including immunotherapy was performed without surgical treatment, which is the same trend as large-sample reports stating that survival is longer when surgical resection is performed ${ }^{18}$.

Due to the difficulty in assessing the efficacy of systemic therapy and the limitation of excluding distant metastasis in most phase II clinical trials, there is no established regimen for primary lesions ${ }^{13}$. In our cases, patients received a dacarbazine single regimen and an anti PD-1 agent (pembrolizumab) as adjuvant systemic therapy and an anti CTLA-4 agent (ipilimumab) with an anti PD-1 agent (pembrolizumab) for advanced and recurrent lesions. Large-scale random trials of anti CTLA-4 and anti PD-1 for malignant mucosal melanoma 
of the head and neck have yet to be carried out ${ }^{19}$, while there are several smaller clinical trials reporting on malignant mucosal melanoma of the entire body, including overall survival and disease-free survival rates. It was possible to compare our hospital's treatment compared to 11.3 months and 12.1 months of survival periods and 2.8 months of disease free survival on average of few small keynote studies of 8 to 16 people whom being treated with immunotherapy exclusively ${ }^{20-22}$.

In our hospital, the average observation period for the group of patients $(n=12)$ who did not undergo immunotherapy was 34.2 months (range, 1-104 months), and the average disease-free survival was 31.3 months (range, 1-104 months). For patients who underwent immunotherapy as a secondary treatment after conventional therapy other than immunotherapy, the average observation period was 93 months, with a disease-free survival of 76 months. For patients who received immunotherapy as the primary treatment $(n=4)$, the average observation period was 19.3 months, and the disease free survival was 16.3 months. As seen in the survival curve of Fig. 4, use of immunotherapy as a secondary treatment exhibited a higher tendency for survival compared to using only systematic regimens other than immunotherapy, but the difference was not statistically significant.

\section{Conclusion}

This report is not a random trial for a particular treatment, but a retrospective study of a previously conducted treatment. In addition, this report had statistical limitations in analyzing treatment methods and their regimens due to small sample sizes. In our clinic, surgical resection is the first choice in operable patients, and adjuvant therapy is administered based on the margin status and permanent pathologic diagnosis. In the case of systemic therapy, for which guidelines remain unclear, immunotherapy was performed when local recurrence or disease progression was diagnosed. In our clinic, overall survival was longer when radiotherapy or immunotherapy was combined with surgery and was longer than in previous reports. This tendency has been improved through development of treatments and immunotherapy ${ }^{23}$. This implies further improvement of treatment methods based on future developments.

\section{ORCID}

Hyounmin Kim, https://orcid.org/0000-0002-1900-4744

Sanghoon Lee, https://orcid.org/0000-0001-9324-0596
In-Ho Cha, https://orcid.org/0000-0001-8259-2190

Hyung Jun Kim, https://orcid.org/0000-0002-3364-9995

Woong Nam, https://orcid.org/0000-0003-0146-3624

\section{Authors' Contributions}

H.K. participated in data collection, performed the statistical analysis and wrote the manuscript. I.H.C. and H.J.K. helped to draft the manuscript. S.L. and W.N. participated in the study design and helped to draft the manuscript. All authors read and approved the final manuscript.

\section{Ethics Approval and Consent to Participate}

This study was approved by the Institutional Review Board of Yonsei University Dental Hospital (IRB No. 2-2019-0075) and the written informed consent was waived by the IRB.

\section{Conflict of Interest}

No potential conflict of interest relevant to this article was reported.

\section{References}

1. Andersen LJ, Berthelsen A, Hansen HS. Malignant melanoma of the upper respiratory tract and the oral cavity. J Otolaryngol 1992;21:180-5.

2. Chang AE, Karnell LH, Menck HR. The National Cancer Data Base report on cutaneous and noncutaneous melanoma: a summary of 84,836 cases from the past decade. The American College of Surgeons Commission on Cancer and the American Cancer Society. Cancer 1998;83:1664-78. https://doi.org/10.1002/(sici)10970142(19981015)83:8<1664::aid-cncr23>3.0.co;2-g

3. Yde SS, Sjoegren P, Heje M, Stolle LB. Mucosal melanoma: a literature review. Curr Oncol Rep 2018;20:28. https://doi. org/10.1007/s11912-018-0675-0

4. Lund VJ, Howard DJ, Harding L, Wei WI. Management options and survival in malignant melanoma of the sinonasal mucosa. Laryngoscope 1999;109(2 Pt 1):208-11. https://doi. org/10.1097/00005537-199902000-00007

5. Sapp JP, Eversole LR, Wysocki GP. Contemporary oral and maxillofacial pathology. 2nd ed. St. Louis: Mosby; 2004.

6. Sun S, Huang X, Gao L, Zhang Y, Luo J, Zhang S, et al. Long-term treatment outcomes and prognosis of mucosal melanoma of the head and neck: 161 cases from a single institution. Oral Oncol 2017;74:115-22. https://doi.org/10.1016/ j.oraloncology.2017.09.020

7. Napierała MJ, Czarnecka AM. Mucosal melanoma - clinical presentation and treatment based on a case series. Oncol Clin Pract 2019;15:223-30. https://doi.org/10.5603/OCP.2019.0001

8. Wu AJ, Gomez J, Zhung JE, Chan K, Gomez DR, Wolden SL, et al. Radiotherapy after surgical resection for head and neck mucosal melanoma. Am J Clin Oncol 2010;33:281-5. https://doi. org/10.1097/COC.0b013e3181a879f5

9. National Comprehensive Cancer Network (NCCN). NCCN clinical 
practice guidelines in oncology: head and neck cancers. Plymouth Meeting: NCCN; 2020:83-7.

10. Mendenhall WM, Amdur RJ, Hinerman RW, Werning JW, Villaret DB, Mendenhall NP. Head and neck mucosal melanoma. Am J Clin Oncol 2005;28:626-30. https://doi.org/10.1097/01. coc.0000170805.14058.d3

11. López F, Rodrigo JP, Cardesa A, Triantafyllou A, Devaney KO, Mendenhall WM, et al. Update on primary head and neck mucosal melanoma. Head Neck 2016;38:147-55. https://doi.org/10.1002/ hed. 23872

12. Gilligan D, Slevin NJ. Radical radiotherapy for 28 cases of mucosal melanoma in the nasal cavity and sinuses. Br J Radiol 1991;64:1147-50. https://doi.org/10.1259/0007-1285-64-768-1147

13. Bartell HL, Bedikian AY, Papadopoulos NE, Dett TK, Ballo MT, Myers JN, et al. Biochemotherapy in patients with advanced head and neck mucosal melanoma. Head Neck 2008;30:1592-8. https:// doi.org/10.1002/hed.20910

14. Manolidis S, Donald PJ. Malignant mucosal melanoma of the head and neck: review of the literature and report of 14 patients. Cancer 1997;80:1373-86. https://doi.org/10.1002/(sici)10970142(19971015)80:8<1373::aid-cncr3>3.0.co;2-g

15. Lazarev S, Gupta V, Hu K, Harrison LB, Bakst R. Mucosal melanoma of the head and neck: a systematic review of the literature. Int J Radiat Oncol Biol Phys 2014;90:1108-18. https://doi. org/10.1016/j.ijrobp.2014.03.042

16. Bachar G, Loh KS, O'Sullivan B, Goldstein D, Wood S, Brown D, et al. Mucosal melanomas of the head and neck: experience of the Princess Margaret Hospital. Head Neck 2008;30:1325-31. https:// doi.org/10.1002/hed.20878

17. Martin JM, Porceddu S, Weih L, Corry J, Peters LJ. Outcomes in sinonasal mucosal melanoma. ANZ J Surg 2004;74:838-42. https:// doi.org/10.1111/j.1445-1433.2004.03185.x

18. Jethanamest D, Vila PM, Sikora AG, Morris LG. Predictors of sur- vival in mucosal melanoma of the head and neck. Ann Surg Oncol 2011;18:2748-56. https://doi.org/10.1245/s10434-011-1685-4

19. Moya-Plana A, Herrera Gómez RG, Rossoni C, Dercle L, Ammari S, Girault I, et al. Evaluation of the efficacy of immunotherapy for non-resectable mucosal melanoma. Cancer Immunol Immunother 2019;68:1171-8. https://doi.org/10.1007/s00262-019-02351-7

20. Hamid O, Robert C, Ribas A, Hodi FS, Walpole E, Daud A, et al. Antitumour activity of pembrolizumab in advanced mucosal melanoma: a post-hoc analysis of KEYNOTE-001, 002, 006. Br J Cancer 2018;119:670-4. https://doi.org/10.1038/s41416-018-02076

21. Weber J, Mandala M, Del Vecchio M, Gogas HJ, Arance AM, Cowey CL, et al.; CheckMate 238 Collaborators. Adjuvant nivolumab versus ipilimumab in resected stage III or IV melanoma. N Engl J Med 2017;377:1824-35. https://doi.org/10.1056/ NEJMoa1709030

22. Si L, Zhang X, Shu Y, Pan H, Wu D, Liu J, et al. A phase Ib study of pembrolizumab as second-line therapy for Chinese patients with advanced or metastatic melanoma (KEYNOTE-151). Transl Oncol 2019;12:828-35. https://doi.org/10.1016/j.tranon.2019.02.007

23. Manton T, Tillman B, McHugh J, Bellile E, McLean S, McKean E. Sinonasal melanoma: a single institutional analysis and future directions. J Neurol Surg B Skull Base 2019;80:484-92. https://doi. org/10.1055/s-0038-1676355

How to cite this article: Kim H, Lee S, Cha IH, Kim HJ, Nam W. Primary malignant mucosal melanoma of the maxillofacial area.

J Korean Assoc Oral Maxillofac Surg 2021;47:76-81. https://doi. org/10.5125/jkaoms.2021.47.2.76 